\title{
Female gender and exogenous progesterone exposition as risk factors for spheno-orbital meningiomas
}

Caroline Apra ${ }^{1,2}$, Paul Roblot ${ }^{3,4}$, Abdu Alkhayri ${ }^{5}$, Caroline Le Guérinel ${ }^{5}$, Marc Polivka $^{6}$, Dorian Chauvet ${ }^{5}$

\author{
${ }^{1}$ Neurosurgery Department, Hôpital Pitié Salpêtrière, Paris, France \\ ${ }^{2}$ Sorbonne Université, Paris, France \\ ${ }^{3}$ Neurosurgery Department, Centre Hospitalo-Universitaire, Bordeaux, France \\ ${ }^{4}$ Université de Bordeaux, France \\ ${ }^{5}$ Neurosurgery Department, Hôpital Fondation Adolphe de Rothschild, Paris, France \\ ${ }^{6}$ Pathology department, Hôpital Lariboisière, Paris, France
}

Corresponding author : Caroline Apra

Neurosurgery Department ; Hôpital Pitié Salpêtrière ; 43-87 bd de l'Hôpital ; 75013 Paris ; FRANCE

caroline.apra@neurochirurgie.fr

Key words: sphenoorbital meningioma, skull base meningioma, progestin, cyproterone acetate, nomegestrol acetate, osteomeningioma

Abstract word count: 250

Manuscript word count : 2,060

Tables : 2

Figures : 1

Abstract: 
Objective: The great heterogeneity of meningiomas is challenging and we need to distinguish relevant subgroups. Spheno-orbital osteomeningiomas (SOOM) constitute a clinically specific entity, with slowgrowing benign osteo-meningiomatous tumors, which recur after surgery in one fourth of cases. Neurosurgical daily practice, supported by the literature, shows that the vast majority of patients with SOOM are women, and we explored whether their epidemiological and hormonal profiles suggest a progesterone influence.

Methods: We retrospectively documented all radiologically and histologically confirmed cases of SOOM operated in 2005-2019 in our institution. We completed the clinical and hormone history by systematic telephone interviews.

Results: In the literature, SOOM occur significantly more often in women than other meningiomas (749/847, 86.4\% versus 73.8\%, p=0.002). Among 175 cases, we included 124 patients, $93.5 \%$ were women, younger than men $(51 \pm 5$ versus $63 \pm 8, p=0.02)$. Women' meningiomas showed more progesterone receptors ( $96.4 \%$ versus 50\%, $\mathrm{p}<0.001$ ). Exogenous hormonal intake, reliable in 82 cases, concerned $83.3 \%(64 / 78)$ of women, with frequent progesterone intake: 13 oestroprogestogenic treatment only, with old-generation progesterone analogs, 41 progesterone analogs (cyproterone acetate, nomegestrol acetate, chlormadinone, promegestone, etonogestrel, levonogestrel), 7 substitutive hormonal therapy for menopause, 3 others. Duration of treatment was 2-40 years, median 10 years.

Conclusions: SOOM develop preferentially in women in their fifties, who often received progesterone analogs, and show progesterone receptors. Progesterone analogs are incriminated in skull base meningiomas, and this is the first report on the prevalence of exogenous hormone therapy specifically in SOOM. Whether SOOM reduce after treatment discontinuation, in particular the osteoma part, needs to be explored. Anti-progesterone treatments may represent an avenue for future research in SOOM. 
Introduction

Meningiomas, the most frequent primitive intracranial tumors, form a heterogeneous group, with growing evidence that anatomical and molecular subgroups must be identified in order to unveil the mechanisms underlying their genesis and clinical evolution ${ }^{1}$. It has been shown that some types of meningiomas develop in specific locations and that the genetic profile of tumors located in the skull base is quite different from the profile of convexity meningiomas ${ }^{2}$. Exogenous factors, such as hormone treatment, that is being increasingly described in meningiomas development, seems to be incriminated in some locations specifically, in particular in the skull base $\mathrm{e}^{3-5}$.

We believe that a precise description of some clinically relevant subgroups of tumors is necessary and we chose to focus on the spheno-orbital meningiomas because clinical practice shows that almost all patients are middle-aged women, and the literature confirms this impression, as described in this study. Spheno-orbital meningiomas form $2-9 \%$ of all meningiomas and can be segregated into a separate entity since they are mostly formed of osteomeningiomas, with grade 1 meningothelial lesions ${ }^{6}$. Spheno-orbital meningiomas are revealed by proptosis in $95 \%$ of cases, associated with visual impairment and oculomotor paresis. When treatment is indicated, surgery is compulsory, with good functional results, but complete resection is not feasible and many cases recur, needing adjuvant radiotherapy or repeated surgery in one fourth of patients ${ }^{6}$. Therefore, there is a high demand for alternative therapeutic strategies in this subgroup of meningiomas. We provide retrospective monocentric epidemiological data about spheno-orbital meningiomas, with one of the largest series of surgical spheno-orbital meningiomas published until now, and we particularly questioned the frequency of exogenous hormone intake, which has never been reported specifically in this subgroup. We do not detail the surgical strategy or results, which have been largely described in the literature already, including by our team, and are quite consensual now ${ }^{6,7}$.

Patients \& methods

All patients operated for a spheno-orbital meningioma and registered in the local database in 20052019 in the neurosurgery department of the Hôpital Fondation Adolphe de Rothschild, Paris, France, were reviewed. We excluded all patients without histological confirmation for a meningioma and all preoperative MRI were reviewed by a senior neurosurgeon, DC, to exclude non typical spheno-orbital locations. Histology was available in all cases and progesterone receptors status was routinely assessed 
by immunochemistry and validated by a neuropathologist (MP). Estrogen receptors were not systematically analyzed. Clinical, pathological and radiological data was retrospectively harbored from the medical file and a telephone interview was systematically performed by CA or PR to complete the information and obtain consent from all the patients. We got exhaustive description of the patients' medical history and hormonal intake.

A literature review was performed by $C A$ in Pubmed with the search terms "sphenoorbital meningiomas" and "spheno-orbital meningiomas", according to the PRISMA guidelines. We included all series published between 2010 and 2019 with histological confirmation and excluded those not detailing the sex of the patients. If one department had published several articles about their series, we chose to use only the largest one, in order to avoid including twice the same patient. We consider that there is no reason to suspect a bias of publication or surgical indication based on the sex of the patients. To obtain a comparative cohort of meningiomas, we used the largest published up-todate meningioma series ${ }^{8}$. Statistical analysis was performed using Excel (Microsoft, Redmond, USA). We used Khi2 test, or exact Fisher test when the conditions of population were not fulfilled.

Results

In our local series, 175 patients were operated for a spheno-orbital meningioma during this period, 124 with complete imaging and histological data. One hundred and sixteen were women (93.5\%) and median age for surgery was significantly younger for females ( $51 \pm 5$ versus $63 \pm 8, \mathrm{Khi} 2, \mathrm{p}=0.02$ ). There was a peak of incidence for women in their fifties (cf figure 1). All meningiomas were associated to an osteoma causing proptosis or loss of vision, which was the indication for surgery. In total, $90.3 \%$ of tumors were meningothelial grade 1 meningiomas (112/124), including all tumors in males, 4 were transitional, 2 atypical, the others angioblastic, psammomatous, secretory and microcystic. Progesterone receptors were found in more than $10 \%$ of cells in meningiomas in $96.4 \%$ of females, and $50.0 \%$ of males, which is significantly higher in women (exact Fisher test, $p<0.001$; IC95\% $[0.0065 ; 0.3345])$.

We could complete a reliable retrospective history for the patients in 82 women and 4 men, and reliable hormone history in 78 women and 4 men, the others could not be contacted after 3 phone calls ( $n=38$, among which at least 2 dead patients), had doubts about taking hormones treatment $(n=4)$ or refused to answer $(n=1)$. Associated diseases included thyroid dysfunction, hypertension, diabetes, and others, as expected in the general population. No patient had received cranial radiotherapy or was 
diagnosed with neurofibromatosis. $8.3 \%$ of patients had multiple meningiomas $(7 / 84,3$ bilateral spheno-orbital meningiomas). No woman was pregnant at the time of diagnosis or surgery, $42 \%$ were premenopausal, $12 \%$ were perimenopausal and $46 \%$ were postmenopausal. Gynecological comorbidities included uterine fibroids, breast fibroadenomas and cancers, ovarian cysts, cervical dysplasias and endometriosis in proportions similar to the general population.

Exogenous hormonal intake concerned 83.3\% (65/78) of female patients, among which 25 were premenopausal, 9 perimenopausal and 31 postmenopausal: 61 patients have a relatively precise hormonal history (13 received only oestroprogestogenic treatment, 41 received progesterone analogs, and 7 received substitutive hormonal therapy for menopause without precision), whereas 2 patients did not remember the type of contraception they took, one patient received only progesterone ointment, one patient reported in vitro fertilization, in addition to 2 patients with ovarian stimulations. (cf figure 1). The molecules are detailed in table 1. All documented oestroprogestogenic pills contained old-generation progesterone analogs. Retrospective recollection of treatment duration was incomplete, and was reported between 2 and 40 years, median 10 years. Among patients with multiple meningiomas, all of them were women and received hormones ( 1 oestroprogestogenic treatment, 4 progesterone analogs, 1 substitutive hormonal therapy for menopause). All patients were advised to stop exogenous hormones intake after surgery.

Repeated surgery was necessary in $21.0 \%$ of patients for recurrent symptoms (26/124, 25 women, 10 premenopausal, 6 perimenopausal and 9 postmenopausal). Among them, information about hormone intake was available in 16: 12 received exogenous progesterone (75\%), 1 received oestroprogestogenic pill (6.5\%), 1 received substitutive hormonal therapy for menopause (6.5\%), and 2 received no hormone (13\%), but one of them had 8 pregnancies. Reliable information about the 48 -year-old male patient could not be obtained retrospectively but erectile dysfunction was mentioned in his medical file, suggesting hormonal abnormality.

$\mathrm{BMI}$ at the time of surgery was difficult to assess reliably in the retrospective cohort, but the mean $\mathrm{BMI}$, in 38 women, was $24.8 \pm 1.8$, with 16 overweight (BMI>25, $42 \%$ ) and 8 obese patients (BMI>30, $21 \%)$. These figures tend to be higher than the general female population in this region, respectively $23.9 \%$ and $10.1 \%$ (Khi2; $\mathrm{p}=0.06$ and $\mathrm{p}=0.07)^{9}$.

In the literature review, we found 83 publications between 2010 and 2019, among which 24 series of spheno-orbital meningiomas, and we excluded 7 series because they lacked some relevant data ${ }^{10-16}$. Two teams published their series twice in this period ${ }^{6,17-19}$, and we excluded the smaller one in each case. Thus, we identified 14 articles each reporting 13 to 130 patients, as detailed in table $2^{6,18,20-31}$. We pooled those cases with our patients to obtain a population of 847 patients with surgical spheno- 
orbital meningiomas. Among them, 749 were women. Statistical analysis showed that the proportion of women among patients with spheno-orbital meningiomas is significantly higher than in patients with meningiomas in general when this literature series is compared with the largest meningiomas series, that describes 81.475 female for 110.359 cases $(86.4 \% \text { versus } 73.8 \% \text {, Khi2, } p=0.002)^{8}$. Other risk factors, such as body mass index, radiation history or hormone intake, were not described in the other series.

\section{Discussion}

Until now, spheno-orbital meningiomas had not been identified as a subgroup of meningiomas particularly prone to hormonal influence, which our study tends to suggest. Indeed, meningiomas develop more often in women than in men $^{8}$, but spheno-orbital meningiomas develop spectacularly more often in women, with $86.4 \%$ of patients being female in our literature review and $93.5 \%$ in our series. The fact that women were significantly younger than men at the time of surgery could also be linked to the fact that spheno-orbital osteomeningiomas might grow more quickly with the female endogenous hormonal exposition. It is difficult to interpret data about pregnancies and menopause, because they are slow-growing tumors usually revealed by proptosis at a late stage, and the time of surgery may not reflect the time of development. Only $6.0 \%$ of patients in our series had multiple meningiomas, which is quite low compared to the literature (up to $38.7 \%{ }^{6}$ ).

We found, by precisely questioning the patients, that the exogenous progesterone exposition seems particularly high in this group. It is challenging to define which treatment should be defined as excessive progesterone intake, since many women take, for instance, oral contraception or substitutive hormonal treatment for menopause. Therefore, we relied on already published data to focus on drugs that have been incriminated before in meningiomas development: they mainly consist of high dose progesterone treatments, especially cyproterone acetate, nomegestrol acetate and chlormadinone, but any type of hormonal treatment could potentially be at risk and was included in our study ${ }^{32,33}$. Levonogestrel has also been reported as inducing meningioma growth ${ }^{34}$. Progesteroneonly contraception is suspected, but it seems that there is no risk increase for oestrogen-only and oestrogen-progesterone contraception ${ }^{4}$. The association of meningiomas with some gynecological comorbidities, such as uterine fibroids, has been described but was not confirmed in our series ${ }^{35}$.

The possibility that hormones dependent meningiomas develop in specific cranial areas has been suggested by a number of publications, especially in the skull base ${ }^{3-5}$, but spheno-orbital meningiomas 
specifically were not reported until now: Passeri et al. reported meningiomas on the sphenoid ridge, the clivus, the clinoid and the frontal convexity that decreased after stopping nomegestrol acetate ${ }^{36}$. Champagne et al. described a parasagittal meningioma that increased with both nomegestrol acetate and cyproterone acetate ${ }^{37}$. Cyproterone acetate discontinuation was reported in decreasing meningiomas of various locations, preferentially the skull base, but no spheno-orbital case $\mathrm{e}^{3,38}$. Harland et al. documented a series of 67 female patients with grade I meningiomas and also found that, in patients who took progesterone-only contraception, there was a tendency for meningiomas located at the skull base compared to patients who took other types of contraception ${ }^{4}$. The anterior skull base predominance was also described by Peyre et al. in cyproterone acetate, megestrol acetate and chlormadinone acetate dependent operated meningiomas ${ }^{5}$. Subcutaneous Levonorgestrel implant has been reported as inducing sphenoid wing meningioma growth ${ }^{34}$. Fertility treatments are also associated with multiple meningiomas in patients younger than the average ${ }^{39}$. Our results show, for the first time, that spheno-orbital meningiomas seem to be a particularly relevant subgroup in analyzing exogenous hormonal intake. Contrary to the other hormonal treatments, fertility treatments were found to increase the risk of convexity meningiomas, which seems consistent with the low proportion of women with a spheno-orbital meningioma having benefited from this type of treatment (only 1 in vitro fertilization and 2 ovarian stimulations).

The limits of our retrospective study are the lack of precision about the treatments duration, doses and even the molecule the patients received, especially because hormonal therapies are often not considered as medication by the patients themselves, or by their surgeon. Bias of recall have been evaluated in the literature before, and it is established that recall of treatment use is relatively reliable, for both oral contraception and hormone replacement therapy, but that the patients have great difficulty remembering the name of the drug and the dates of use ${ }^{33}$. To improve the quality of recall in future studies, interviews should be based on drug lists or photo prompts. In addition, we were not able to contact all patients, and only part of the cohort could be analyzed. These limits should however not impact the sex ratio or overestimate the prevalence of exogenous hormones intake in the population.

As compared to other published cases, our series focuses on surgically treated and histologically confirmed spheno-orbital meningiomas, and therefore cannot answer a central therapeutic question: how often do spheno-orbital meningiomas regress after stopping hormonal therapy? We need to know more about the natural history of spheno-orbital meningiomas, for instance in patients who do not have visual impairment. The fact that no spontaneous regression of spheno-orbital meningiomas has been described before in patients taking progesterone analogs yet may be due either to the scarcity of reported cases compared to the clinical experience of each neurosurgeon, or to the fact that an 
osteoma is associated and symptomatic in most cases, and might not regress as often as the meningeal part of the tumor. The results in our series about this question are incomplete and inconclusive: although the 3 patients with bilateral spheno-orbital osteomeningiomas did not need contralateral surgery, $21 \%$ of operated patients needed ipsilateral reintervention despite having stopped hormonal treatment, even in 9 post-menopausal women. Thus, we observe that, once the spheno-orbital meningioma has developed, stopping the treatment will not systematically lead to tumor regression.

Although meningiomas hormonal dependency is now well established, the mechanisms underlying this risk factor are not understood yet. Factors include endogenous and exogenous hormonal sources: sex, age, overweight, treatments. On the histological point of view, progesterone receptors are present in about $70 \%$ of the meningiomas, a property that has been described for many years now ${ }^{40}$. There is conflicting evidence about the correlation between the sex of the patient and the presence of progesterone or estrogen receptors ${ }^{41,42}$. However, it seems that progesterone receptors are more expressed in progestin-dependent meningiomas, although they are not found in all cases ${ }^{5}$. There is no evidence linking the quantity of hormone receptors to tumor growth under treatment, and, conversely, progesterone receptors are regularly found in patients who never took hormonal treatments. In our series, spheno-orbital meningiomas in women had significantly more progesterone receptors than the rare cases found in men (96.4\% versus $50 \%$ ), which seems to confirm the role of endogenous or exogenous progesterone on the tumor's growth. The exact type and proportion of receptors need to be described more thoroughly in those cases.

In general, progesterone receptor expression is a good prognostic sign, particularly when considered with a low mitotic index and a low grade ${ }^{43}$, but this is apparently not the case in spheno-orbital meningiomas, with a high rate of symptomatic recurrences in grade 1 meningothelial tumors. Unfortunately, most histological studies do not detail the localization of meningiomas enough to identify spheno-orbital meningiomas specifically, and we suspect spheno-orbital meningiomas were systematically excluded from some studies, since complete resection of the osteoma and the en plaque part cannot be achieved ${ }^{44}$. The progesterone inhibitor mifepristone has been proposed to treat recurrent or unresectable meningiomas with a good efficacy in vitro, but it had contradictory results in vivo, with minimal or temporary efficacy in some cases, which could mean that we still lack criteria to predict which patients will benefit from it ${ }^{45-47}$. This type of treatment may represent an avenue for future research in spheno-orbital meningiomas specifically. In addition, a particular molecular profile for spheno-orbital meningiomas has not been described yet, but there is evidence that specific locations are associated with specific molecular patterns, in particular mutations in TRAF7/AKT1 and SMO are found in meningiomas that develop in the anterior fossa, median middle fossa, or anterior calvarium, most of them being meningothelial or transitional meningiomas ${ }^{2,48}$. There is also evidence 
that exogenous hormones may induce specific molecular profiles in meningiomas, with a higher frequency of PIK3CA and TRAF7 mutations ${ }^{5}$.

Conclusion

Spheno-orbital meningiomas are a homogeneous subgroup of meningiomas, with an important osseous part, nearly all being grade I tumors with progesterone receptors, that typically develop in women in their fifties, a large proportion of which have received high-dose progesterone in their lifetime. Our study is the first report on the prevalence of exogenous hormone therapy specifically in spheno-orbital meningiomas. Systematic recollection of hormonal history at the time of diagnosis is necessary and additional epidemiological or histological data may help understand specific molecular patterns found in these tumors. Progesterone inhibitors may represent an avenue for future research in this specific type of osteomeningiomas, to complete the surgical management in frequent recurrent cases.

Legend:

Table 1: Detailed exogenous hormone intakes in 61 women with spheno-orbital meningiomas (78.2\%); 41 received progesterone therapies and 13 only oestroprogestogenic treatments, all containing oldgeneration progesterone. The remaining 7 received substitutive hormonal treatment for menopause, without precision. In addition, 2 received contraception pills they could not remember, 1 progesterone ointment and 1 underwent in vitro fertilization, so that $64 / 78$ (83.3\%) received exogenous hormones.

Table 2: Literature review of series of spheno-orbital meningiomas in 2010-2019. The number of female patients is detailed in the third column. Compared to the largest series of meningiomas in general (Dolecek et al., 20128), spheno-orbital meningiomas develop significantly more often in women $(p=0.002)$. 
Figure 1: Description of patients with operated spheno-orbital meningiomas A: Age repartition of patients with a spheno-orbital meningioma, solid line: women, dotted line: men, with a 5 years mean. Age of surgery is significantly lower in females, and there is a peak of incidence in women around 5152 years ( $51 \pm 5$ versus $63 \pm 8, p=0.02$ ). B: Repartition of exogenous hormone intake in 78 women with spheno-orbital meningiomas ; 41 received progesterone therapies ; 13 received only oestroprogestogenic treatments ; 7 received substitutive hormonal treatment for menopause.

Disclosure: the authors declare no conflict of interest. The authors declare no funding. 
1. Youngblood MW, Duran D, Montejo JD, et al. Correlations between genomic subgroup and clinical features in a cohort of more than 3000 meningiomas. J Neurosurg. Published online October 25, 2019:1-10. doi:10.3171/2019.8.JNS191266

2. Yuzawa S, Nishihara H, Tanaka S. Genetic landscape of meningioma. Brain Tumor Pathol. 2016;33(4):237-247. doi:10.1007/s10014-016-0271-7

3. Bernat AL, Oyama K, Hamdi S, et al. Growth stabilization and regression of meningiomas after discontinuation of cyproterone acetate: a case series of 12 patients. Acta Neurochir (Wien). 2015;157(10):1741-1746. doi:10.1007/s00701-015-2532-3

4. Harland TA, Freeman JL, Davern M, et al. Progesterone-only contraception is associated with a shorter progression-free survival in premenopausal women with WHO Grade I meningioma. J Neurooncol. 2018;136(2):327-333. doi:10.1007/s11060-017-2656-9 5. Peyre M, Gaillard S, de Marcellus C, et al. Progestin-associated shift of meningioma mutational landscape. Ann Oncol Off J Eur Soc Med Oncol. 2018;29(3):681-686. doi:10.1093/annonc/mdx 763

6. Terrier L-M, Bernard F, Fournier H-D, et al. Spheno-Orbital Meningiomas Surgery: Multicenter Management Study for Complex Extensive Tumors. World Neurosurg. 2018;112:e145-e156. doi:10.1016/j.wneu.2017.12.182

7. Scarone P, Leclerq D, Héran F, Robert G. Long-term results with exophthalmos in a surgical series of 30 sphenoorbital meningiomas. Clinical article. J Neurosurg. 2009;111(5):1069-1077. doi:10.3171/2009.1.JNS081263

8. Dolecek TA, Propp JM, Stroup NE, Kruchko C. CBTRUS Statistical Report: Primary Brain and Central Nervous System Tumors Diagnosed in the United States in 2005-2009. Neuro-Oncol.2012;14(suppl_5):v1-v49.doi:10.1093/neuonc/nos218 9. Vincelet C, Galli J, Grémy I. Surpoids et obésité en Ile-de-France. Obs Régional Santé. Published online May 2006.

10. Belinsky I, Murchison AP, Evans JJ, et al. Spheno-Orbital Meningiomas: An Analysis Based on World Health Organization Classification and Ki-67 Proliferative Index. Ophthal Plast Reconstr Surg. 2018;34(2):143-150. doi:10.1097/IOP.0000000000000904

11. Civit T, Freppel S. [Sphenoorbital meningiomas]. Neurochirurgie. 2010;56(2-3):124131. doi:10.1016/j.neuchi.2010.02.022

12. Mariniello G, Bonavolontà G, Tranfa F, Maiuri F. Management of the optic canal invasion and visual outcome in spheno-orbital meningiomas. Clin Neurol Neurosurg. 2013;115(9):1615-1620. doi:10.1016/j.clineuro.2013.02.012

13. Nagatani K, Takeuchi S, Otani N, Nawashiro H. Surgical management of sphenoorbital meningiomas. Acta Neurochir (Wien). 2011;153(7):1541; author reply 1539-1540. doi:10.1007/s00701-011-1037-y

14. Peron S, Cividini A, Santi L, Galante N, Castelnuovo P, Locatelli D. Spheno-Orbital Meningiomas: When the Endoscopic Approach Is Better. Acta Neurochir Suppl. 2017;124:123-128. doi:10.1007/978-3-319-39546-3_19

15. Shapey J, Jung J, Barkas K, et al. A single centre's experience of managing sphenoorbital meningiomas: lessons for recurrent tumour surgery. Acta Neurochir (Wien). 2019;161(8):1657-1667. doi:10.1007/s00701-019-03977-3

16. Spuler A. [Spheno-orbital meningiomas: how to follow up and for how long?]. HNO. 2010;58(1):35-36. doi:10.1007/s00106-009-2047-4

17. Saeed P, van Furth WR, Tanck M, et al. Surgical treatment of sphenoorbital meningiomas. Br J Ophthalmol. 2011;95(7):996-1000. doi:10.1136/bjo.2010.189050

18. Saeed P, van Furth WR, Tanck M, et al. Natural history of spheno-orbital meningiomas. Acta Neurochir (Wien). 2011;153(2):395-402. doi:10.1007/s00701-010-0878-0 
19. Yannick N, Patrick F, Samuel M, et al. Predictive factors for visual outcome after resection of spheno-orbital meningiomas: a long-term review. Acta Ophthalmol (Copenh). 2012;90(8):e663-665. doi:10.1111/j.1755-3768.2012.02419.x

20. Forster M-T, Daneshvar K, Senft C, Seifert V, Marquardt G. Sphenoorbital meningiomas: surgical management and outcome. Neurol Res. 2014;36(8):695-700. doi:10.1179/1743132814Y.0000000329

21. Freeman JL, Davern MS, Oushy S, et al. Spheno-Orbital Meningiomas: A 16-Year Surgical Experience. World Neurosurg. 2017;99:369-380. doi:10.1016/j.wneu.2016.12.063 22. Gonen L, Nov E, Shimony N, Shofty B, Margalit N. Sphenoorbital meningioma: surgical series and design of an intraoperative management algorithm. Neurosurg Rev. 2018;41(1):291-301. doi:10.1007/s10143-017-0855-7

23. Honig S, Trantakis C, Frerich B, Sterker I, Schober R, Meixensberger J. Sphenoorbital meningiomas: outcome after microsurgical treatment: a clinical review of 30 cases. Neurol Res. 2010;32(3):314-325. doi:10.1179/016164109X12464612122614

24. Kiyofuji S, Casabella AM, Graffeo CS, Perry A, Garrity JA, Link MJ. Sphenoorbital meningioma: a unique skull base tumor. Surgical technique and results. J Neurosurg. Published online August 23, 2019:1-8. doi:10.3171/2019.6.JNS191158

25. Leroy H-A, Leroy-Ciocanea CI, Baroncini M, et al. Internal and external sphenoorbital meningioma varieties: different outcomes and prognoses. Acta Neurochir (Wien). 2016;158(8):1587-1596. doi:10.1007/s00701-016-2850-0

26. Maschke S, Martínez-Moreno M, Micko A, et al. Challenging the osseous component of sphenoorbital meningiomas. Acta Neurochir (Wien). 2019;161(11):2241-2251. doi:10.1007/s00701-019-04015-y

27. Oya S, Sade B, Lee JH. Sphenoorbital meningioma: surgical technique and outcome. $J$ Neurosurg. 2011;114(5):1241-1249. doi:10.3171/2010.10.JNS101128

28. Schick U. [Sphenoorbital meningiomas: results in long-term treatment]. HNO. 2010;58(1):37-43. doi:10.1007/s00106-009-2024-y

29. Solmaz I, Tehli O, Temiz C, et al. Surgical strategies for the removal of sphenoorbital meningiomas. Turk Neurosurg. 2014;24(6):859-866. doi:10.5137/1019-5149.JTN.10336-14.3 30. Terpolilli NA, Ueberschaer M, Niyazi M, et al. Long-term outcome in orbital meningiomas: progression-free survival after targeted resection combined with early or postponed postoperative radiotherapy. J Neurosurg. Published online June 14, 2019:1-11. doi:10.3171/2019.3.JNS181760

31. Young J, Mdanat F, Dharmasena A, et al. Combined neurosurgical and orbital intervention for spheno-orbital meningiomas - the Manchester experience. Orbit Amst Neth. Published online October 28, 2019:1-7. doi:10.1080/01676830.2019.1673782

32. Claus EB, Calvocoressi L, Bondy ML, Wrensch M, Wiemels JL, Schildkraut JM. Exogenous hormone use, reproductive factors, and risk of intracranial meningioma in females. J Neurosurg. 2013;118(3):649-656. doi:10.3171/2012.9.JNS12811

33. Wigertz A, Lönn S, Mathiesen T, Ahlbom A, Hall P, Feychting M. Risk of Brain Tumors Associated with Exposure to Exogenous Female Sex Hormones. Am J Epidemiol. 2006;164(7):629-636. doi:10.1093/aje/kwj254

34. Piper JG, Follett KA, Fantin A. Sphenoid wing meningioma progression after placement of a subcutaneous progesterone agonist contraceptive implant. Neurosurgery. 1994;34(4):723-725; discussion 725. doi:10.1227/00006123-199404000-00022

35. Carroll RS, Glowacka D, Dashner K, Black PM. Progesterone receptor expression in meningiomas. Cancer Res. 1993;53(6):1312-1316.

36. Passeri T, Champagne P-O, Bernat A-L, et al. Spontaneous regression of meningiomas after interruption of nomegestrol acetate: a series of three patients. Acta Neurochir (Wien). 2019;161(4):761-765. doi:10.1007/s00701-019-03848-x 
37. Champagne P-O, Passeri T, Froelich S. Combined hormonal influence of cyproterone acetate and nomegestrol acetate on meningioma: a case report. Acta Neurochir (Wien). 2019;161(3):589-592. doi:10.1007/s00701-018-03782-4

38. Bernat AL, Bonnin S, Labidi M, et al. Regression of Giant Olfactory Groove Meningioma and Complete Visual Acuity Recovery after Discontinuation of Cyproterone Acetate. J Ophthalmic Vis Res. 2018;13(3):355-358. doi:10.4103/jovr.jovr_21_17

39. Shahin MN, Magill ST, Dalle Ore CL, et al. Fertility treatment is associated with multiple meningiomas and younger age at diagnosis. J Neurooncol. 2019;143(1):137-144. doi:10.1007/s11060-019-03147-6

40. Donnell MS, Meyer GA, Donegan WL. Estrogen-receptor protein in intracranial meningiomas. J Neurosurg. 1979;50(4):499-502. doi:10.3171/jns.1979.50.4.0499

41. Korhonen K, Salminen T, Raitanen J, Auvinen A, Isola J, Haapasalo H. Female predominance in meningiomas can not be explained by differences in progesterone, estrogen, or androgen receptor expression. J Neurooncol. 2006;80(1):1-7. doi:10.1007/s11060-0069146-9

42. Carroll RS, Glowacka D, Dashner K, Black PM. Progesterone receptor expression in meningiomas. Cancer Res. 1993;53(6):1312-1316.

43. Hsu DW, Efird JT, Hedley-Whyte ET. Progesterone and estrogen receptors in meningiomas: prognostic considerations. J Neurosurg. 1997;86(1):113-120.

doi:10.3171/jns.1997.86.1.0113

44. Roser F, Nakamura M, Bellinzona M, Rosahl SK, Ostertag H, Samii M. The prognostic value of progesterone receptor status in meningiomas. J Clin Pathol. 2004;57(10):1033-1037. doi:10.1136/jcp.2004.018333

45. Ji Y, Rankin C, Grunberg S, et al. Double-Blind Phase III Randomized Trial of the Antiprogestin Agent Mifepristone in the Treatment of Unresectable Meningioma: SWOG S9005. J Clin Oncol Off J Am Soc Clin Oncol. 2015;33(34):4093-4098.

doi:10.1200/JCO.2015.61.6490

46. Sharma R, Garg K, Katiyar V, et al. The role of mifepristone in the management of meningiomas: A systematic review of literature. Neurol India. 2019;67(3):698-705.

doi:10.4103/0028-3886.263232

47. Touat M, Lombardi G, Farina P, Kalamarides M, Sanson M. Successful treatment of multiple intracranial meningiomas with the antiprogesterone receptor agent mifepristone (RU486). Acta Neurochir (Wien). 2014;156(10):1831-1835. doi:10.1007/s00701-014-2188-4 48. Boetto J, Bielle F, Sanson M, Peyre M, Kalamarides M. SMO mutation status defines a distinct and frequent molecular subgroup in olfactory groove meningiomas. Neuro-Oncol. 2017;19(3):345-351. doi:10.1093/neuonc/now276 
Table 1: Literature review of series of spheno-orbital meningiomas in 2010-2019. The number of female patients is detailed in the third column. Compared to the largest series of meningiomas in general (Dolecek et al., $2012^{8}$ ), spheno-orbital meningiomas develop significantly more often in women $(\mathrm{p}=0.002)$.

\begin{tabular}{|c|c|c|}
\hline Reference & N. of patients & N. of women \\
\hline Honig et al., $2010^{22}$ & 30 & 22 \\
\hline Schick et al., $2010^{27}$ & 77 & 61 \\
\hline Saeed et al., $2011^{17}$ & 90 & 85 \\
\hline Oya et al., $2012^{26}$ & 39 & 34 \\
\hline Solmaz et al., $2014^{28}$ & 13 & 3 \\
\hline Forster et al., $2014^{19}$ & 18 & 18 \\
\hline Leroy et al., $2016^{24}$ & 70 & 64 \\
\hline Freeman et al., $2017^{20}$ & 25 & 23 \\
\hline Terrier et al., $2018^{6}$ & 130 & 119 \\
\hline Gonen et al., $2018^{21}$ & 27 & 24 \\
\hline Mashcke et al., $2019^{25}$ & 31 & 27 \\
\hline Young et al., $2019^{30}$ & 24 & 22 \\
\hline Kiyofuji et al., $2019^{23}$ & 47 & 38 \\
\hline Terpolilli et al., $2019^{29}$ & 122 & 93 \\
\hline Our series & 124 & 116 \\
\hline TOTAL & 867 & 749 \\
\hline
\end{tabular}


Table 2: detailed exogenous hormone intakes in 61/78 women with spheno-orbital meningiomas $(78.2 \%) ; 40$ received progesterone therapies (51.3\%) and 13 only oestroprogestogenic treatments, all containing old-generation progesterone. The remaining 8 received substitutive hormone treatment for menopause, without precision.

\begin{tabular}{|c|c|c|c|c|c|c|c|}
\hline \multicolumn{3}{|c|}{ Progesterone therapies } & \multicolumn{5}{|c|}{ Oestroprogestogenic therapies } \\
\hline Treatment & Molecule & $\begin{array}{c}\text { N. of } \\
\text { patients }\end{array}$ & Treatment & Oestrogen & Progesterone analog & $\begin{array}{c}\text { Progesterone } \\
\text { generation }\end{array}$ & $\begin{array}{c}\text { N. of } \\
\text { patients }\end{array}$ \\
\hline ANDROCUR & $\begin{array}{l}\text { Cyproterone acetate } \\
50 \mathrm{mg}\end{array}$ & 9 & $A D E P A L$ & $\begin{array}{l}\text { Ethinylestradiol } \\
0.030-0.040 \mathrm{mg}\end{array}$ & Levonogestrel $0.15-0.20 \mathrm{mg}$ & 2 & 1 \\
\hline COLPRONE & Medrogestone 5mg & 1 & DIANE 35 & $\begin{array}{l}\text { Ethinylestradiol } \\
0.035 \mathrm{mg}\end{array}$ & Cyproterone acetate $2 \mathrm{mg}$ & 2 & 2 \\
\hline LUTENYL & $\begin{array}{l}\text { Nomegestrol acetate } \\
5 \mathrm{mg}\end{array}$ & 14 & GYNOPHASE & $\begin{array}{l}\text { Ethinylestradiol } \\
0.050 \mathrm{mg}\end{array}$ & Norethisterone acetate $1-2 \mathrm{mg}$ & 1 & 1 \\
\hline LUTERAN & Chlormadinone $5-10 \mathrm{mg}$ & 13 & GYNOVLANE & $\begin{array}{l}\text { Ethinylestradiol } \\
0.050 \mathrm{mg}\end{array}$ & Norethisterone acetate $2 \mathrm{mg}$ & 1 & 1 \\
\hline SURGESTONE & Promegestone $0.5 \mathrm{mg}$ & 1 & MINIDRIL & $\begin{array}{l}\text { Ethinylestradiol } \\
0.030 \mathrm{mg}\end{array}$ & Levonogestrel $0.15 \mathrm{mg}$ & 2 & 4 \\
\hline $\begin{array}{l}\text { NEXPLANON - } \\
\text { CONTRACEPTIVE } \\
\text { IMPLANT }\end{array}$ & Etonogestrel & 2 & MINIPHASE & $\begin{array}{l}\text { Ethinylestradiol } \\
0.030-0.040 \mathrm{mg}\end{array}$ & Norethisterone acetate $1-2 \mathrm{mg}$ & 1 & 1 \\
\hline $\begin{array}{l}\text { INTRAUTERINE } \\
\text { CONTRACEPTIVE } \\
\text { DEVICE }\end{array}$ & Levonogestrel & 1 & $\begin{array}{l}\text { CONTRACEPTIVE } \\
\text { OESTROGENIC } \\
\text { PILL }\end{array}$ & - & - & - & 4 \\
\hline & & 40 & & & & & 13 \\
\hline
\end{tabular}



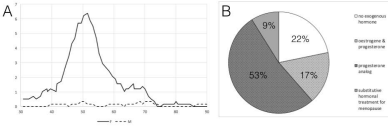